\title{
Have Your Cake and Eat It, Too? The Practical Challenges Executives Face with the Mutual Gains Approach to Negotiations
}

\author{
Katarzyna Jagodzinska
}

\begin{abstract}
Winning a negotiation is undeniably the most desirable outcome for most negotiators. Unfortunately, a focus on one-sided gains rarely leads to sustainable agreements. In today's competitive business environment it is therefore essential to reach a negotiation outcome that not only bridges the interests of both parties, but also enforces the relationship between them. While the idea that negotiators should strive towards mutually acceptable solutions has already been examined in literature, few studies address the practical challenges that executives face when they apply the mutual gains approach to negotiations in modern business practice.

This article introduces a systematic 6-step process, which encompasses the key elements of the mutual gains approach to negotiation and the challenges that business executives typically face with the application of each element. The study provides a straightforward and user-friendly framework that can be used to prepare for a negotiation or at any time during a negotiation to avoid the most common mistakes and boost the chances of reaching executable agreements.
\end{abstract}

Index Terms-Negotiation, Reaching Agreement, SelfManagement, Principled Negotiation, Positional Bargaining, Win-Win Solutions, Executable Agreement.

\section{INTRODUCTION}

Negotiation is a fairly formalized process during which two parties with different needs try to reach a mutually accepted agreement about the distribution of limited resources [1]. Needs are dictated by threefold underlying interests: common, different and conflicting. On the example of a pharmaceutical company with different divisions, common interests are those shared by all the departments, such as the going concern of the enterprise. Sales representatives primarily want to close transactions quickly in order to meet their sales quota in a given quarter, the operations team on the other hand needs time to prepare proper paperwork that is free from error; both departments thus have different interests. The clash between delivering high quality products or services vs. speed of delivery can best serve to illustrate a conflicting interest.

The predominant reason why people negotiate is linked to the scarcity of resources. Parties therefore engage in negotiating to establish who will get "a slice of the cake" and what size the piece will be. An important indicator of a successful negotiation outcome is the maximization of the limited resource. One of the ways to achieve this is by

Published on May 15, 2020.

Katarzyna Jagodzinska, University of Neuchatel, Switzerland.

(corresponding e-mail: k.jagodzinska@onet.eu) choosing an appropriate approach to negotiation: distributive or integrative. The former approach means distributing (cutting) the resource in order to get the most for oneself or the party one represents. Integrating, on the other hand, aims at maximizing the benefits for oneself and all the parties involved.

Recognizing the various interests of the negotiating partners and applying an integrative approach to negotiation alone do not guarantee that a solution which satisfies both parties will be reached. In order to boost the chances of arriving at an executable outcome, one needs to master all the other elements that come into play in the course of negotiation: objective and engagement, investigation of interests and positions, separation of people (and oneself) from the problem, reference to objective criteria, creation of options for mutual gain, exploration of the Best Alternative to Negotiated Agreement (BATNA), and proper communication between parties. Each constituent of the 6step process to win-win negotiations will now be presented and the challenges faced by executives will be explained with reference to examples from business practice.

\section{THE FOUR MOST COMMON NEGOTIATION STRATEGIES}

\section{A. Competition}

Referred to as the "power struggle", "law of the jungle" or the "win-lose" approach. Competing involves a whole array of verbal, non-verbal and para-verbal communication aimed at making the other party comply with our demands. It is often characterized by aggressive or insulting behaviors, making the other party feel uncomfortable or weak, stating demands instead of investigating mutual interests, reluctance to making concessions and trying to have our needs met at all costs. This approach seldom leads to sustainable agreements that link the task (negotiation objective) and relationship aspect. It may be a recommended strategy in one-off transactions, for example the sale of a used vehicle where the buyer and seller both just want to strike the best deal and have no regard for future cooperation.

\section{B. Manipulation}

Often involves influencing the other party into compliance by veiled behavior (false flattery for example) and information gathering rather than investigation of shared interests and transparent communication. Consequently, the connotations that this approach triggers are in most part unfavorable. However, manipulation can be understood in two ways. In the negative sense it relates to getting the other party to do something that he/she would never freely choose 
to, and which stands contrary to his/her interests. A more positive outlook is known "as influence work". It means getting the other party to do something that he/she might not have chosen out of his/her own will, but that is not necessarily contrary or detrimental to his/her interests. As noted earlier, negotiation involves two parties with different needs trying to reach a mutually accepted agreement. By definition it is a two-sided process of persuading and convincing. Noteworthy, the key to ethical solutions is exercising the influence in such a way as to satisfy our own needs and steer the other party towards compliance without detriment to his/her wants, needs and negotiation goals.

\section{Compromise}

Is one of the easiest and fastest means of distribution of a limited resource, which does not require too much time or creative effort on the part of the negotiating partners. In contrast to competition, a compromise does not mean that the winner takes it all. Ironically, it is in fact another winlose or lose-win approach to negotiation. In the course of concessions both parties gain and lose something. As a visualization tool, compromise is often represented as an orange cut in two, of which one half goes to each party. The urban negotiation tale of two sisters quarreling over who will get the orange ends in their splitting the fruit in half. This is a fair and quick fix, but it is hardly the best one as will be explained further in the article.

\section{Principled Negotiation (The Win-Win Approach)}

The theory of principled negotiation was developed by Harvard Professor Roger Fisher and his colleague, Dr. William Ury in Harvard in the 1980s and made famous by the popular book Getting to Yes [2]. The theory has been transformed into a methodology - the systematic approach to negotiation. It has become synonymous with the more popular phrase "win-win" - originally taken from Game Theory. Contrary to positional bargaining, which as the name itself suggests, means locking oneself in a fixed position, principled negotiation leads to an agreement that, by definition, should be: 1) efficient in the distribution of the resource(s), 2) fair to both sides and 3) reinforcing the relationship between both parties. This approach involves, among others, finding arrangements by identifying the interests behind the positions and determining which needs are fixed and which are flexible for negotiators, and then finding creative options to bridge those needs.

\section{THE ESSENTIAL ELEMENTS OF THE MUTUAL GAINS APPROACH}

The 6 key constituents of the mutual gains strategy are: common objective and engagement of the parties, distinction between interests and positions, separation of people from the problem, reference to objective criteria and creation of options for mutual gain, establishment of a Best Alternative to Negotiated Agreement (BATNA) and effective communication.

These elements are visually presented in Figure 1. The circular form illustrates the fact that the constituents function as a continuum, and each step compliments the other in a quest for reaching a long-lasting negotiation and executable outcomes. It is noteworthy to draw attention to the difference between deal-makers and real-makers. Dealmakers are popular protagonists in literature on the topic of negotiators. They do not necessarily function equally well in real life situations. Real-makers are the true real-life heroes. These negotiators manage not only to close a deal, but to finalize it in such a way that the negotiated terms are actually implemented and executed. It is fairly easy to sign a contract; the challenge is whether that agreement will be respected by both parties and whether it will stand the test of business.

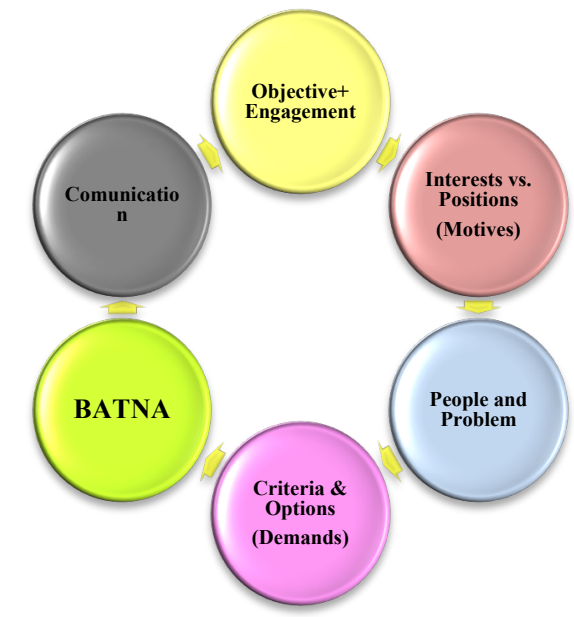

Fig. 1. The 6 essential elements of the mutual gains approach

My professional activities in the capacity of Consultant for the United Nations, Professor and International Consultant in negotiation have allowed me to work with students, executives, business professionals from Europe, the Middle East and the USA, and UN officials. In the business simulations and interactive discussions that constitute an integral part of my lectures and training sessions, I have used all the above-mentioned approaches to negotiation. I have also put them to the test on the occasions when I was appointed to act as a negotiator for individual clients or the UN stakeholders. Based on my experiences I noticed that while the application of the win-win strategy seems easy in theory, the integration of the 6 key elements in real life business is quite often a challenging undertaking.

\section{A. Finding a common objective and engaging the parties}

Negotiation is an art, which to a large extent relies on the ability to successfully persuade others [3]. Most people display a utilitarian mindset. Their predominant concern is with their own benefit. They are driven by the question: what's in it for me. As already established, at the heart of each negotiation are threefold underlying interests: common, different and conflicting. The role of the negotiator is to firstly identify what are all the interests in a given situation. The practical question is then which interest to start the negotiation with. Addressing the common ones is more likely to build a bond between the parties. This is the somewhat idyllic approach that is often recommended by theorists. Some practitioners tend to prefer addressing the different and conflicting interests first, although they may present more challenges. Commencing with the differentiating factors may well be a way of bumper-testing if the parties can work together at the outset. Regardless of which approach is chosen, in order to steer the process 
towards a more participative and collaborative direction one has to find ways to involve the other party in the negotiation process, even if in a symbolic sense, in order to create a feeling of working in unison towards a common goal.

One of the phases of the process of persuasion is framing goals on common ground. This involves pointing out the shared advantages of your proposal and providing vivid evidence to support it [4]. Sometimes this may require staging the setting to enforce cooperation between the parties, provided of course that two-sided advantages objectively exist.

During one particularly long and complex negotiation of a future joint venture between a company based in Dubai and a firm in Paris, I found my creativity as a negotiation facilitator taken to the test. The cultural differences evident in the divergent approach to time and the negotiation process itself, as well as the exhaustion from the back and forth communication (characterized by completely different styles of the high and low context cultures) were clouding the chances of closure in the foreseeable future. After lengthy discussions and many exchanges of redline documents, the representatives of the two companies came to a standstill. We ran the risk of the deal falling through. Eager to overcome the blockage, I went over the details of what was discussed up to that point. I could not find any serious barriers to agreement, such as legal, administrative or financial obstacles. In short, the analyses and due diligence clearly showed that both parties objectively shared a common goal: the setting-up of the joint venture in view of internationalization their activities. I came to the conclusion that what was missing in order to conclude the agreement was full understanding and engagement of both parties in the process.

I therefore decided to schedule a meeting with the representatives of both parties on neutral territory, in a meeting room at Frankfurt airport where both could fly in and out after the reunion. My role was to act as an intermediary between the two parties. I came well prepared and with a concrete goal to move things forward. The aim of the meeting was to present the soft copy of the documents with the changes proposed by the Paris team to the partner from Dubai, which would then hopefully push the discussions forward. When we all arrived, the parties chose where they would sit. Not surprisingly under the circumstances of blockage, the two partners chose seats opposite each other. This was not a good start for overcoming a deadlock and steering towards a more cooperative dynamic.

I decided to try out a little experiment on them. I set up my workspace and started looking for the latest version of the agreement that only I had. After a moment I looked up and said: "It seems our secretary forgot to pack enough copies for us all. I only have one copy here with me. Would you mind sharing it?" To my surprise, the partners agreed to this without hesitation. Immediately they sat side by side to facilitate the work with one document between them. After all, neither wanted to be at a disadvantage by having to read the document upside down. Shoulder to shoulder with two pens in different colors and one contract version, the parties engaged in the process of discussing the terms and proposing modifications that could be acceptable for both companies. The atmosphere quickly changed from confrontational to cooperative both in room setting and in spirit. We managed to overcome the impasse in the course of just one workday. What was the secret behind this sudden change in dynamics? It was the engagement of the parties in the sense that both proposed changes and discussed them instead of sending "my version" and "your version" back and forth. More importantly, in this interaction nothing was imposed, but rather it was a process of two-sided ownership in a quest for the best possible solution that would push the deal forward.

Finding a common objective can be challenging, especially if both counterparts only see their side of the transaction. A negotiation is a relation of inter-dependency between two people: I need you and you need me to close the deal. A critical condition for engagement is for the counterpart to firstly feel understood and respected. Many executives erroneously think that granting the courtesy of understanding and respect is a sign of weakness. On the contrary, the party who can manage their emotions, keep an open mind, set the tone as well as the expectations is the one who drives the process. Furthermore, understanding is the key to gathering information and, on that basis, identifying what are the objectives of the counterpart. This then allows to choose the right strategy and tactics for the execution of the negotiation. It is vital to avoid imposing solutions, rather the other party should feel that they have been involved, under your carefully thought through guidance, in the process. Involvement in the decision-making process reduces the risk of the terms of agreement being broken.

The above experiment uncovers one other interesting fact. The moment executives exchange redline versions, they develop the endowment effect [5]. Even if the goal is to reach agreement, they become opponents: my version against your version of the document. Neither wants to let their version go. This often leads to deadlock. Should this be the case, it is recommended to apply creative solutions for engaging both parties. Such solutions should fall outside of the standard set of negotiation tactics or worse yet manipulation that the other party can see through and naturally be discouraged by. The best ones seem to be those that engage natural, instinctive reactions, such as sitting side by side over one set of documents. Certainly, one can think of other such ideas for remote interactions.

\section{B. Making a distinction between interests and positions}

The urban negotiation myth is the story of two sisters who are arguing over the distribution of one orange. Both want the fruit. They spend a lot of time and energy in exchanging arguments who should get it. In the end, they fail to find the most efficient resolution of their problem. They end up cutting the orange in half. As it later turns out, one sister wanted to make orange juice and the other needed the peel of the orange to add flavor to a cake she was baking. Under these circumstances satisfying the needs of one sister did not exclude or even limit the satisfaction of the needs of the other. What was the problem then? They both stayed locked in their positions and all their energy was directed at defending them. Eventually this led to a phenomenon that is referred to as "tunnel vision". Just like the light in the tunnel narrows, so does the ability of the parties to see beyond their 
rigid demands. Once this happens creating options other than one-sided becomes difficult.

It is fairly easy to find out what the position of the other party is. The "what do you want" (at least in monetary terms) often surfaces when the first offer is made. This opening proposal, if carefully crafted, then serves as an anchor to the subsequent negotiation. When preparing the opening offer, it is therefore vital to take the time to gather useful information in order to choose an anchoring closest to the other party`s barely acceptable terms, and to be able to justify it with objective criteria. Excessive anchoring, understood as the risk of asking more than our partner finds reasonable, may lead to either the chilling (loss of interest in the negotiation) or the boomerang (an equally excessive counteroffer) effect and ruin the negotiation at the outset. The mitigation of this risk alone does not guarantee a successful negotiation. All it ensures is that the process kicks off.

The opening offer can thus be considering as the "what" part of the equation. However, in order to maximize the limited resource and lead to an agreement that has the potential for durability, the parties have to explore both the "what" and the "why" questions. Instead of focusing on their positions - the "What do you want?" the orange sisters could have investigated the motives driving these positions and asked one simple question: "Why do you want it?" Interests and positions can best be mentally illustrated on the example of an iceberg. Positions are above the waterline, while interests are below. Interests are driven by, among others, individual needs and preferences. At any point in time human behavior is driven by a continuum of needs according to Maslow's theory. It is the role of a skilled negotiator to dive in and grasp the understanding of the whole picture.

Many executives seek advice on how to proceed with exploring the interests behind the positions expressed by their counterparts. A negotiation is not a confession and asking the "why" question point blank will seldom be awarded with the true reasons. Books on communication repeatedly suggest asking open questions. This is a halfsolution. It is a good strategy in the sense that it will unveil information about the other person. People reveal themselves in talking. Their choice of words and what they express is an indication of many factors: their personality, attitude, emotional state, intellectual standing, intercultural sensitivity, moral and ethical standards, education level, social class, international exposure and many other aspects. By intentional listening it is possible to understand the mental map of the other party - their inner GPS system that directs the behavior. The more one uncovers, the easier it becomes to understand what drives the behavior of our counterpart and what motivates them. It is thus important to ask open questions that are directed towards achieving a specific goal, not just shooting open questions. One needs to be careful in order not to design and pose questions that serve the confirmation bias. The point of the exercise is to uncover new information, not to confirm what one thinks they already know. The best way is to keep an open ear(s) and assume we never know enough.

Intentional listening with an aim of understanding the interests behind the verbalized position means hearing not only the words, but also the contextualization of behavior. It calls for a paradigm shift on the part of the "interest investigator" - the ability to see the different angles of a given subject. Power and status symbols, the choice of profession and type of lifestyle are all helpful indicators in profiling our counterpart and grasping the meaning of why they are making a specific demand.

\section{Separating people (and oneself) from the problem}

Typically, we tend to equate the difficulties we face with the person we are dealing with. If we cannot get what we want we often tend to attribute the fault to the personality traits of the other person (she is stubborn, he always needs to have things done his way, she cannot control her emotions, he is too competitive, etc). Hence so many books have been written on managing "difficult people" and conducting difficult conversations [6]. Pointing a finger at the other person is certainly easier than admitting that the process in negatively impacted by our own shortcomings, perception errors or flawed logic. The core of the issue is the inability to separate the people, including ourselves, from the problem.

The trend to turn the tables, or rather the mirror, around is budding in literature on negotiation. It is being recognized that long-term negotiations require achieving a triple win: the classic win-win between the two parties and an individual (internal) win [7]. In my seminars I teach the participants that the first step to negotiation is not preparation as many authors suggest [8], but rather selfpreparation. Any negotiation should start with selfmanagement: taking control of ones` emotions, automatic impulses, unconscious reactions, ego and embedded patterns of learned behavior. If one cannot manage their own self and apply rational thinking free of judgment, prejudices, bias, and stereotypes, then the chances of balancing the task and relationship part of the negotiation process are highly unlikely.

Why is drawing a line between people and oneself, and the problem so important? Firstly, it frees up the mental energy that should be directed at finding a joint solution to the distribution arrangement that both parties are sharing. Secondly, doing so does not detriment the relationship between the parties, a crucial yet very elusive element of sustainable agreements. Thirdly, it does not cloud the logic like excessive reliance solely on emotions might [9].

Separating the people from the problem can be achieved by managing emotions. Emotions are like our internal GPS system; they cannot and should not be switched off. Nonetheless, they need to be kept in guard. The human brain is built in such a way that when the external trigger enters, we first feel then we think. It is therefore physically not possible to be emotional and rational at the same time.

Based on the stories shared by the executives I trained, here are some tips on how to deal with people who are trying to intimidate or threaten us by making personal attacks rather than concentrating on the dilemma. The most important is to break the cycle between success and intimidation and instead to consciously steer the discussion towards the negotiation agenda. This can be achieved by not reacting to behavior we find unacceptable or simply by asking for a break to calm down. Many executives question 
whether asking for a break when things get heated will not be seen as a weakness on their part. Quite the contrary, it is wiser to take a moment off then make a decision that will be regretted later. This approach is not to be mistaken with avoidance, which is simply doing nothing. The time-out technique is referred to as "going on the emotional balcony". The balcony designates a place, away from the main stage of the negotiation events, where we can cool off and look at the situation from a fresh perspective. My training experience shows that distancing oneself constitutes one of the main difficulties for many people. As one of the participants recently said during one of our sessions when we were talking about the emotional balcony: "I don't think I've ever been there before". Have you?

Once back from the balcony, we can express our feelings without sending the other side on a guilt or anger trip. Instead of criticizing, becoming defensive or making personal attacks it is recommended to describe how we feel. Each person has the right to express how something feels. A nice formula that can be recommended is as follows: "I feel (express emotion) when you do (define act/behavior) because (reason)". Focusing on the problem and not on the person can best be done my making the other party understand that they will obtain what they want only by negotiating on the merits of the case. It is often helpful to steer the discussion back to the common objective of the negotiation.

If necessary, one might recall the rules of the negotiation game: "I need that we agree on how to work together." Finally, a good technique may also be posing an open question in a deliberate effort to involve the other party in the process: "How can we achieve our common goal?" This empowers the other party and allows them to take ownership of the process, under our reigns.

A common mistake that executives make is labelling: this is a difficult client, tricky account, tough negotiation, etc. The moment you internally or externally label the negotiation as challenging, it has just become ten times (figuratively speaking) as difficult. This is the effect of subjective priming. The emotions will be activated for expected difficulties and the level of stress hormones will rise. Rational reactions are at risk of being limited or overlooked. This is not to say that preparation should not include the anticipation of obstacles that will inevitably cause certain difficulties to surface. This is part of the negotiation game, or any human interaction for that matter. The trick is to take it for what it is and not add to the distress by attributing negative labels.

\section{Referring to objective criteria and creating options for expanding the cake}

This step can best be described on the example of one of the classics of negotiation simulation cases. The case involves the sale of a vintage automobile. The car is a unique one; it is in top shape, has recently undergone a refurbishment and has only been used for short country escapades by its rich owner who prides himself on his collection of luxury vehicles. The potential buyer is a wealthy widow who recently experienced the death of her husband, a very controlling man who liked to take all the decisions on their behalf. She sees the car during her vacation and immediately falls in love with it. She sends her representative to negotiate the terms of the transaction with the secretary of the owner. The widow has a budget of $\$ 55,000-65,000$. The seller's desired price for this unique car is $\$ 60,000-70,000$. In financial terms, there exists a Zone of Possible Agreement (ZOPA) - the overlap between the most the buyer is willing to pay and the least the seller is willing to accept.

This imaginary negotiation is a reflection of a real-life one, it includes both subjective and objective factors. One of the subjective elements is the principal-agent relationship. Both the widow and the car owner have representatives acting on their behalf. These individuals have their own stakes in the negotiation: they are responsible for the outcome of the negotiation (its success or failure, the negotiated price and any additional extras, etc.), they wish to please their agents and prove their self-worth in the process. The seller and buyer are also driven by subjective forces. The widow has a desire to finally make her own decisions and not be taken for a fool while at it. The car owner wants the car to go to good hands. Naturally, both want the best price too.

As discussed earlier, one of the conditions of a sustainable agreement is the exploration of the interests behind the positions. However, unlike in the anecdote about the orange sisters, this negotiation involves more than just distributing (or ideally maximizing) the limited resource. What differentiates it is the fact that a monetary value has to be assigned and accepted in order to even consider maximizing the benefits for both parties. Ironically, if the agents get caught up solely in the subjective elements, specifically their own motivations and those of their principals, they run the risk of going into positional bargaining rather than applying the principled approach. Positional bargaining would mean setting a price based purely on the subjective value of the transaction to each party. Naturally, we tend to overestimate the real value of things that are special for us, this is the aforementioned endowment effect in action. One of the ways to avoid foggy judgment is by referring to objective criteria: the market value of similar vehicles, the type of refurbishment work performed, the number of labor hours spent, the cost of replacement parts, etc. in order to establish a fair price for the automobile. Failure to refer to objective criteria will lead to a time and energy consuming battle of subjective arguments. This is hardly a constructive dynamic.

The second step on the road to reaching an agreement would be the creation of options that maximize the ZOPA. Here a savvy negotiator makes room for the subjective elements that are important from the point of view of both parties. This is where the demands are introduced. A negotiation is an exercise in trade, the counterparts exchange something of less value for something of more value. By making space for the subjective elements in the transaction, the agents secure both the task and the relationship, which allows them not only to close the transaction, but possibly also open the gates to a future cooperation. In the fictional negotiation example, the creative options could involve among others inviting the widow and her friends (other potential buyers) to a special show of other vintage cars on the part of the seller or a commitment to bring her friends to 
see the showcased vehicles on the part of the buyer. The sky is the limit when it comes to crafting creative options.

The challenges that executives encounter regarding the opportunities of expanding the resource relate to the limited demands that they bring to the table. The demands constitute what is referred to as the negotiation mass. Before each negotiation it is recommended to prepare at least ten demands and code them according to the level of their importance: must have, should have and nice to have. This helps to systemize the chips for trade and earmark those which ones can be used for making concessions (not to be confused with compromise). From my experience, business professionals prepare too little demands. They limit their own options before the negotiation even starts. Even worse, they take away their own bargaining power, because the party that brings demands to the table is ultimately the one that drives the negotiation. In other words, failure to place demands and think of creative options for their acceptance is a serious barrier to achievement of the negotiation objective. One might wonder why this mistake occurs. Creativity takes time, energy and mental effort. One of my training participants asked me once: "Can we afford to spend time on preparing demands and then creating options for expanding the pie?" My answer was: can you afford not to?

I also observed that even if the executives prepare a set of demands, they lack conviction when they present them to the counterpart. The standard behaviors include expressing them with hesitation, doubt, an apologetic tone, as a shy request, as a question or with a shower of justifications that directly follows. The moment you justify is the moment that you send the other party a signal that you do not believe that you deserve something. Predators strike at the sign of weakness. If you do not believe it yourself, why would the other party grant you that courtesy? Consequently, a lot of time is spent in trainings on making the participants feel that they have a legitimate right to make demands. Surprisingly, this is the part that makes people the most uncomfortable. This feeling of discomfort triggered by making a demand will naturally reduce the creative capabilities. Excessive stress reduces the ability to think "outside of the box".

\section{E. Establishing a BATNA}

As shown on the earlier example, options are created "inside" the negotiation with the other party either jointly in the form of a brainstorming session or via an individual exploration of potential solution(s). The beauty of creative options is that both parties can receive some benefits from incorporating them into the negotiation process. This fits well with the spirit of the mutual gains approach. Nonetheless, real-life negotiation is seldom an exercise in philanthropy. Although the ideal negotiation outcome is characterized by an optimized and applicable agreement, a better relationship between the parties, no resentment or bitterness, a feeling of shared satisfaction and a desire to do business again, it should also be better than the alternatives or the cost of non-agreement. This Plan B is referred to as the Best Alternative to Negotiated Agreement (BATNA). BATNA should not be mistaken with creative options. The latter are used to bridge the gap in case of lack of a ZOPA when both parties nonetheless want to conclude an agreement, for example in cases when the relationship is more important than the financial merits. The best alternative is created "outside" the negotiation - it is the fall- back position in case the negotiation fails; as such it can be implemented unilaterally.

One of the things that I learned while watching my lawyer mom prepare her clients for court proceedings was the importance of mental empowerment. She meticulously went over the details of each case, but a great part of her efforts went into crafting and strengthening the clients' alternatives, in case things would not go the way they planned in court. The result: her clients walked into the courtroom with an aura of confidence and inner strength resulting from the fact that they had (or believed to have) an ace up their sleeve. She was rewarded with a very high success rate of the cases she won.

In the course of my negotiation practice I have observed that the worst thing to do is to enter the negotiation with an "I have a knife on my throat" attitude, depicting that it is either this or nothing for me in this negotiation. Following my mom's example, the first thing I therefore do when I prepare my clients for important negotiations is to boost their inner bargaining power by helping them realize that there are always alternatives. They either already exist or need to be crafted. In this case it is recommended to "bite more than you can chew". The more alternatives, the greater the confidence.

Executives often have difficulties with believing in their alternatives. The result: they enter the negotiation with a palpable aura of self-doubt. I call their attention to what I refer to as "mirror negotiation". The mirror reflects perceived reality; it is a powerful tool that can be used either for deception or mental seduction. What we display in terms of self-assurance, inner status and authority can reflect in the action of our counterpart and ultimately affect their willingness to cooperate with us.

The traditional approach to negotiation training revolves around the use of tactics and power plays against the other party. However, it neglects the importance of selfmanagement with the aim of creating attachment and bonding, the critical elements on the path to reaching real and long-lasting agreements. Here are a few practical tips on how to design a back-up plan that have worked for the executives I trained. Firstly, identify all the plausible things you might do without the other party, in case you are unable to reach an agreement. Once this is done, calculate the value associated with each alternative. Select which of these alternatives is best...this is your BATNA. Remember to always try to anticipate and analyze the other parties' BATNAs with equal care and objectivity. Strongly believe that your alternatives are valid. Make it known to the other party that you have external options but never reveal your real BATNA. Finally, believe that you are still the best alternative for your negotiation partner, otherwise they would not be at the negotiation table!

\section{F. Communicating effectively}

PMI's Pulse of the Profession In-Depth Report the Essential Role of Communications revealed that 56\% of projects are at risk solely due to ineffective communication [10]. Moreover, most performance reviews rate ineffective communication as the main reason of managerial failure. A 
negotiation is nothing else than the attempt to introduce a new project - a proposal to maximize the limited resource by distributing it in such a way as to harness one's own interests and those of the other party. Communication is the only means of conveying that offer. Effective communication should work on three levels: verbal (words, content), non-verbal (appearance, gestures, body language, physical distance, bodily reactions) and para-verbal (flow, tone, intonation, pitch of voice, accents, latency period between words, silence). For it to be perceived as authentic, there has to be a balance between all three levels [11]. This means that the recipient will only perceive the message as real if there is no dissonance - the spoken message reflects the non-verbal and para-verbal behavior of the speaker. In that sense effective communication is an art of perception management [12]. As stated by Jung, perception is the only reality [13]. People react based on their perceptions of reality, not on reality itself.

Perception should therefore be crafted on two levels: internally and externally. We can stage the impact we want to have on the other person by careful choice of words, the way in which we convey our demands and by paying attention to body language. Internally the challenge is linked to managing the negative emotions related to the anticipation of rejection, which is at the source of rejection's destructive power [14]. The paralyzing fear of rejection far too often governs how (or whether at all) we verbalize our proposals and how the other person perceives them.

The importance and breadth of communication merits a separate study, hence for the purposes of this article I will only concentrate on the aspects that pertain to the skills effective negotiators should consider including in their bargaining repertoire in order to avoid the risk of failure of their negotiating efforts.

Table 1 presents a comparison of some of the most effective communication techniques contrasted with behaviors that should be avoided. It will constitute the basis for the presentation of the most frequent communication mistakes that executives make in their business negotiations.

\section{TABLE I [15]}

\begin{tabular}{|c|c|}
\hline Effective negotiators & Effective negotiators avoid \\
\hline $\begin{array}{l}\text { Label their behavior, which allows the } \\
\text { other side to anticipate what comes next: } \\
\text { "May I ask you a question..." or "I } \\
\text { would like to explain my point of view } \\
\text { regarding your analysis....". }\end{array}$ & $\begin{array}{l}\text { Irritating words: e.g. "You } \\
\text { must understand that ..." } \\
\text { or } \\
\text { "I am making you a generous } \\
\text { offer" }\end{array}$ \\
\hline $\begin{array}{l}\text { Frequently test the other party's } \\
\text { understanding by regularly taking stock } \\
\text { of the situation, stopping to make } \\
\text { summaries and partial reviews }\end{array}$ & $\begin{array}{l}\text { Counter-proposals when } \\
\text { formulated immediately in } \\
\text { response to proposals made by } \\
\text { the other party }\end{array}$ \\
\hline $\begin{array}{l}\text { Express their emotions, feelings and } \\
\text { reflections }\end{array}$ & $\begin{array}{l}\text { Argument overkill: i.e., } \\
\text { producing too many reasons } \\
\text { to support a position }\end{array}$ \\
\hline $\begin{array}{l}\text { Carefully prepare } \\
\text { options }\end{array}$ & $\begin{array}{l}\text { Defending their rigid } \\
\text { positions }\end{array}$ \\
\hline $\begin{array}{l}\text { Set objectives in the form of a range, } \\
\text { rather than a fixed figure }\end{array}$ & $\begin{array}{l}\text { The emotional spiral: attack } \\
\text { / defense / attack, } \\
\text { or criticism / justification / } \\
\text { criticism }\end{array}$ \\
\hline Maintain a flexible negotiation process & $\begin{array}{l}\text { Dead-end and irrelevant } \\
\text { debates }\end{array}$ \\
\hline
\end{tabular}

There is a saying: "He who complies against his will is of his opinion still". It shows that people do not react well to imposed solutions, states or worldviews of others.
Consequently, telling your counterpart that they must understand something sends a dual message: of enforcing combined with underestimating their mental capability. This is a recipe for an immediate defensive attitude, which will make navigating towards a more cooperative path more challenging.

Another common mistake that executives make is presenting and evaluating an offer from their own perspective or offering subjective solutions too quickly without having heard out and understood the other party. It is not possible to modify an attitude by telling someone to change or do something. In order to impact the behavior, one needs to first address the affective, and then the cognitive elements in the system that makes up an attitude. When an external trigger enters the brain, people first feel (the amygdala reacts) then they think and rationalize, and finally act. Therefore, our judgements and choices are nothing else than a reflection of endorsed and rationalized feelings. A skilled negotiator understands that the aim of communication - to influence people's behavior - can only be obtained by respecting the feel-think-act sequence.

Many executives struggle to find the best arguments to support their offer and the demands they are making. They waste a lot of time and energy on producing reasons to support their positions. In doing so, they are only really convincing themselves and their egos. The other party will inevitably reciprocate by pulling out their artillery of arguments. The result is a never-ending debate that ultimately causes both parties to lose sight of the objective of the negotiation. In some cases, this may lead to an emotional spiral of attack/defense or criticism/justification. With reference to the attitudinal aspects resulting from the brain structure, it is not possible to be emotional and rational at the same time. Things communicated under the influence of emotions often make the best speeches that will forever be regretted having been given. The end result may be an impasse or a deadlock, in extreme cases a ruined relationship. This is definitely not a fertile ground for exploring the options of reaching a sustainable agreement.

In the negotiations I have moderated I often heard the parties say: "I understand, but..." followed by a counterproposal. These three words are what I refer to as communication quicksand. Intuitively most people know that what follows after the "but" is the exact opposite of what the other party just expressed. The phrase "I understand" is only a buffer used to soften the counter-offer. It has little to do with real comprehension, in fact it may even highlight the exact opposite. Negotiation is not an exercise in oratory skills. In order to master the art of persuasion, executives need to understand what is driving the feelings, thoughts and actions of the counterpart. Communication starts with listening and not with talking. The ratio should ideally be $80: 20$.

\section{CONCLUSION}

This article is the fruit of my experiences gained from teaching students and conducting negotiation trainings for United Nations officials and executives from all over the world and from a wide array of business industries and sectors. The initial aim of the study was to introduce a 
hybrid 6-step model that could be used to boost the chances of reaching executable and long-lasting agreements. My strong conviction, based purely on theory, was that it is possible to "have the cake and eat it, too", an idea that resonated well with the hedonistic spirit of our times. My professional activities allowed me to test the theoretical assumptions of the mutual gains approach against business practice, be it in the course of negotiation simulations or real-life business negotiations. I observed many practical challenges that both students and executives face when they apply the mutual gains approach to negotiations in modern business practice. This triggered the question what needs to happen for both parties to have it all in a negotiation.

One of the first landmarks on the path to arriving at mutually satisfying and sustainable agreements is the exploration of interests, desires and preoccupations underlying the other parties' positions and their demands. The main barrier is a one-sided focus on our own motives and needs, which clouds our understanding of what is driving the behavior of our counterpart.

Provided that the true issues are uncovered, it is recommended to invent options to maximize the mutual benefit, without transforming them into yet another war of positions. In order to do so, a skilled negotiator can propose to base the budding agreement on objective criteria that are independent of the parties' wishes. In order to increase the chances of closing a mutually acceptable deal, the negotiator needs to radiate an aura of competence and inner confidence that comes from having a backup plan and knowing at the outset what to do if the other party breaks the negotiation. This can be achieved by continually exploring alternatives to the negotiated agreement. As mentioned, negotiation is not only an exercise in influence. It is also a fine art of self management reflected in the ability to control one's emotions and to manage the perceptual process of the other party. A characteristic trait of someone who can stand his or her ground is the ability to be open and assertive.

In order to reach a mutually acceptable solution, it is necessary to examine the other side's proposals. These are conveyed through verbal, non-verbal and para-verbal communication. Listening with empathy, showing the other party that you understand their point of view (not to be confused with agreeing with it), consulting and involving them in any decision that concerns them in substance are good ways to build a connection. Empowerment is a more effective tool than imposition.

An effective negotiation should balance the task and relationship aspects of the process. It is not favored to try to improve a bad relationship by making concessions or to try to obtain concessions by threatening the relationship. The problem should never be associated with the person; rather efforts should be made to tackle the obstacles jointly with the other party. This creates a bond between the negotiation partners.

Negotiation involves reaching agreement about the distribution of a limited resource. This often evokes various emotions of the counterparts who have common, different and conflicting interests. The challenge is to express these feelings without attacking the other side or being governed by ones' subjective perception of events, which will ultimately blur the ability to propose a mutually satisfying outcome.

To conclude, the 6-step framework is a good tactical basis for negotiating executable agreements. However, it is not sufficient if applied in isolation. Focus on the technical aspects and one-sided gains will not lead to lasting and executable agreements, no matter how well tactically the parties have been trained. To successfully conclude a business deal, the task related aspects of a negotiation need to be leveraged with the underlying emotional factors that govern the behavior of the parties at the negotiation table. I encourage you to apply a synergistic approach in your next negotiation. You might be pleasantly surprised to find that negotiating can be a piece of cake, and one that can be enlarged.

\section{REFERENCES}

[1] Jagodzinska, K., 2016. Egotiation is the New Negotiation: The Concept of Negotiation Revisited, Eurasian Journal of Business and Management, 4(2), 72-80 DOI: 10.15604/ejss.2016.04.02.007.

[2] Fisher, R., Ury, W.L., Patton, B.M., 2012. Getting to Yes. Negotiating agreement without giving in. New York: Random House Business Books.

[3] Goldstein, N. J., Martin, S. J., Cialdini, R. B., 2013. YES! 50 Secrets from the science of persuasion. Profile Books.

[4] Conger, J. A., 2013. The Necessary Art of Persuasion, HBR's 10 must reads on communication, Harvard Business Review Press, Boston, Massachusetts.

[5] Kahneman, D., 2012. Thinking, Fast and Slow. PenguinBooks, pp. $289-299$.

[6] Stone, D., Patton B., Heen, S., 2010. Difficult conversations. How to discuss what matters most, Penguin Books.

[7] Ury, W., 2015. Getting to yes with yourself (and other worthy opponents). HarperCollins.

[8] Thompson, L., 2008. The truth about negotiations. Pearson Education Ltd.

[9] Fisher, R., Shapiro, D., 2006. Beyond reason. Using emotions as you negotiate. Penguin Books.

[10] For the full report please visit: http://www.pmi.org//media/pmi/documents/public/pdf/learning/thoughtleadership/pulse/the-essential-role-of-communications.pdf (Consulted: March 2020)

[11] Morgan, N., 2013. How to Become an Authentic Speaker HBR's 10 must reads on communication, Harvard Business Review Press, Boston, Massachusetts.

[12] Jagodzinska, K., 2016. How to Manage Perception to Win Negotiations, International Journal of Social Science Studies, Vol. 4, No. 2, ISSN 2324-8033 E-ISSN 2324-8041 Redfame Publishing.

[13] Jung, C., G., (1968). Man and His Symbols. Dell Publishing.

[14] Jiang, J., (2016). Rejection Proof. How to beat fear and become invincible. Random House.

[15] Rackham, N., Carlisle, J., 1978. The Effective Negotiator - Part I: The Behaviour of Successful Negotiators, Journal of European Industrial Training, Vol. 2 Iss: 6, pp.6-11. 